\title{
Dynamic Characteristics and Seismic Response Analysis of Self-anchored Suspension Bridge
}

\author{
Zhang Lianzhen ${ }^{1, a}$, Chen Tianliang ${ }^{1, b}$ \\ ${ }^{1}$ School of Transportation Science and Engineering, Harbin Institute of Technology, Harbin City, \\ China, 150090 \\ aemail:Zhanglianzhen79@163.com, bemail:tzunchan@gmial.com
}

\begin{abstract}
Keywords: Self-anchored suspension bridge, Dynamic characteristics, Time-integration analysis, Geometry nonlinear effect, Seismic response.
\end{abstract}

\begin{abstract}
Self-anchored suspension bridge is widely used in Chinese City bridge engineering for the past few years. Because the anchorage system of main cable has been changed from anchorage blocks to the ends of the girder, its' dynamic mechanics behavior is greatly distinguished with the traditional earth anchored suspension bridge. This paper studies the dynamic characteristics and seismic response of one large-span self-anchored suspension bridge which is located in China/Shenyang city. Using a spatial dynamic analysis finite element mode, the dynamic characteristics are calculated out. An artificial seismic wave is adopted as the ground motion input which is fitted with acceleration response spectrum according to the Chinese bridge anti-seismic design code. Time-integration method is used to get the seismic time-history response. Geometry nonlinear effect is considered during the time-history analysis. At last, the dynamic characteristics and the behavior of earthquake response of this type bridge structure are discussed clearly. The research results can be used as the reference of seismic response analysis and anti-seismic design for the same type of bridge.
\end{abstract}

\section{Introduction}

Self-anchored suspension bridge is widely used in Chinese City bridge engineering in recent years. The first one of this type bridge was constructed in 2000 in China mainland. In the following ten years, there are at least thirty self-anchored suspension bridges which are finished in China. Because of its' esthetics performance and good mechanics behavior, Self-anchored suspension bridge has become new favorite structure for bridge design engineer[1].

The mechanical behavior of self-anchored suspension bridge is different from that of the traditional earth anchored suspension bridge because the anchorage system of main cable has been changed from anchorage blocks to the ends of the girder[2]. Considering the characteristic of this type bridge, the girder is subjected to bending moment as well as axial force which is the huge horizontal component of the cable force. This mechanical character of the girder will bring the P-delta nonlinear effects which can reduce the bending stiffness of the bridge contrast to traditional earth anchored suspension bridge, which will enlarge the natural period of vibration of the self-anchored suspension. Besides, to balance the up-vertical component of the cable force, the huge additional mass block will be placed in the range of girder ends. The huge additional mass block also has an impact on the dynamic characteristics of self-anchored suspension bridge. Therefore, it is very necessary to study the dynamic characteristics of this type bridge.

To understand the seismic response pattern of self-anchored suspension bridge is also important, especially for those bridges which are located in strong seismic region. Self-anchored suspension bridge is a self balance structure system. That is to say, the girder have weaker constrain boundary 
condition to satisfy the longitudinal movement induced by temperature and compress deflection. When the earthquake occurs, the girder will create longitudinal floating movement, the tower will bear huge horizontal earthquake force.

In this paper, taking one large-span self-anchored suspension bridge engineering as a case, the author study the dynamic characteristics and seismic response of this type bridge structure. Using a spatial dynamic analysis finite element mode, the dynamic characteristics are calculated out. An artificial seismic wave is adopted as the ground motion input which is fitted with acceleration response spectrum according to the Chinese bridge anti-seismic design code. Time-integration method is used to get the seismic time-history response. Geometry nonlinear effect is considered during the time-history analysis. At last, the dynamic characteristics and the behavior of earthquake response of this type bridge structure are discussed clearly.

\section{Project overview and finite element model}

The object bridge is located in China/Shenyang City, which is a component of ring way crossing Hunhe River. The bridge is a single-pylon self-anchored suspension bridge. Its' span arrangement is $48 \mathrm{~m}+2 \times 180 \mathrm{~m}+48 \mathrm{~m}$. The main girder is a steel box girder with a height of $4 \mathrm{~m}$ and a width of $42.5 \mathrm{~m}$. The pylon has height of $90.969 \mathrm{~m}$ from the top of pile caps to the tip of the pylon. Fig. 1 shows the architectural effect figure of the bridge.

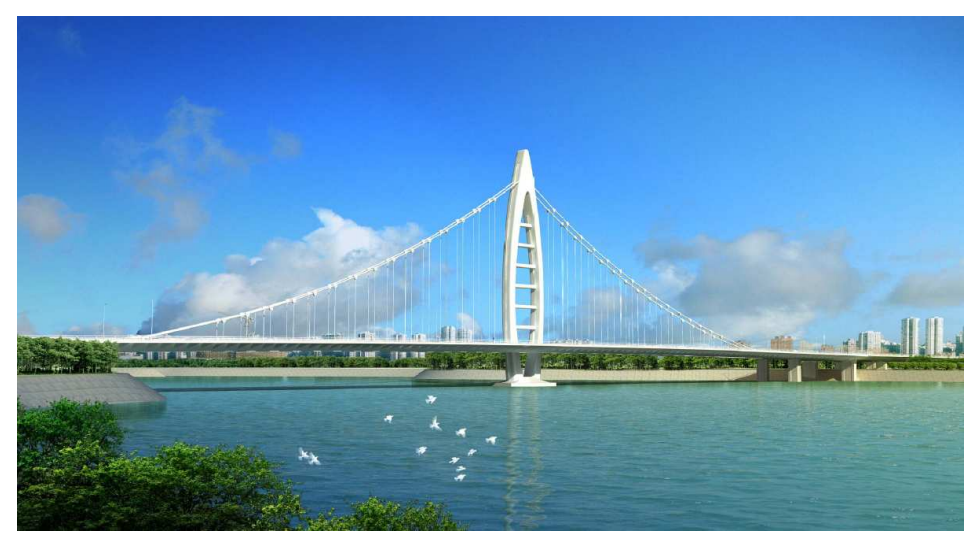

Fig.1 Architectural effect figure of the Bridge

To simulate the structural stiffness and mass distribution accurately and perform the dynamic analysis, a three-dimensional model of the bridge was built in SAP2000 software. Frame type elements are used to model the girder, pylons. Cable type elements are used to model the main cables and hangers. Respectively, the inter-force of final bridge balance state is integrated into the geometric stiffness matrix as initial conditions.

\section{Dynamic characteristics analysis of the bridge}

On the basis of finite element model, subspace iteration method is applied to perform the modal analysis. The preliminary 500 step frequencies and the modes of vibration have been calculated. As space is limited, only the front 10 step modes are enumerated in Table 1 below.

Owing to the small lateral stiffness of the pylon, the transverse bending of the pylon becomes the first vibration mode. Therefore, the response of pylon under horizontal earthquake should be key consideration during the anti-seismic design. 
In the light of the front 50 step modes, it can be found that the structure frequency distribution range is closely space. There are 7 step modes in a frequency range from $0 \mathrm{~Hz}$ to $1 \mathrm{~Hz}$, and 11 step modes with an extensive coverage of frequency from $1 \mathrm{~Hz}$ to $2 \mathrm{~Hz}$. That is to say, coupling effect between the adjacent vibration modes is very prominent. Therefore, many modes can be aroused simultaneously in all probability. The shapes of main vibration modes are showed in Table 2 .

Table 1 The natural frequency and corresponding vibration mode of the bridge

\begin{tabular}{ccc}
\hline Mode no. & Frequency[Hz] & Mode description \\
\hline 1 & 0.455 & Lateral bending mode of the pylon \\
2 & 0.660 & Vertical asymmetric bending mode of the deck \\
3 & 0.798 & Vertical symmetric bending mode of the deck \\
4 & 0.812 & Lateral asymmetric sway mode of the two span cables \\
5 & 0.813 & Lateral sway mode of the right span cables \\
6 & 0.813 & Lateral sway mode of the left span cables \\
7 & 0.835 & Lateral symmetric sway mode of the two span cables \\
8 & 1.396 & Lateral asymmetric sway mode of the two span cables \\
9 & 1.397 & Lateral sway mode of the right span cables \\
10 & 1.397 & Lateral sway mode of the left span cables \\
\hline
\end{tabular}

Table 2 Shapes of main vibration modes

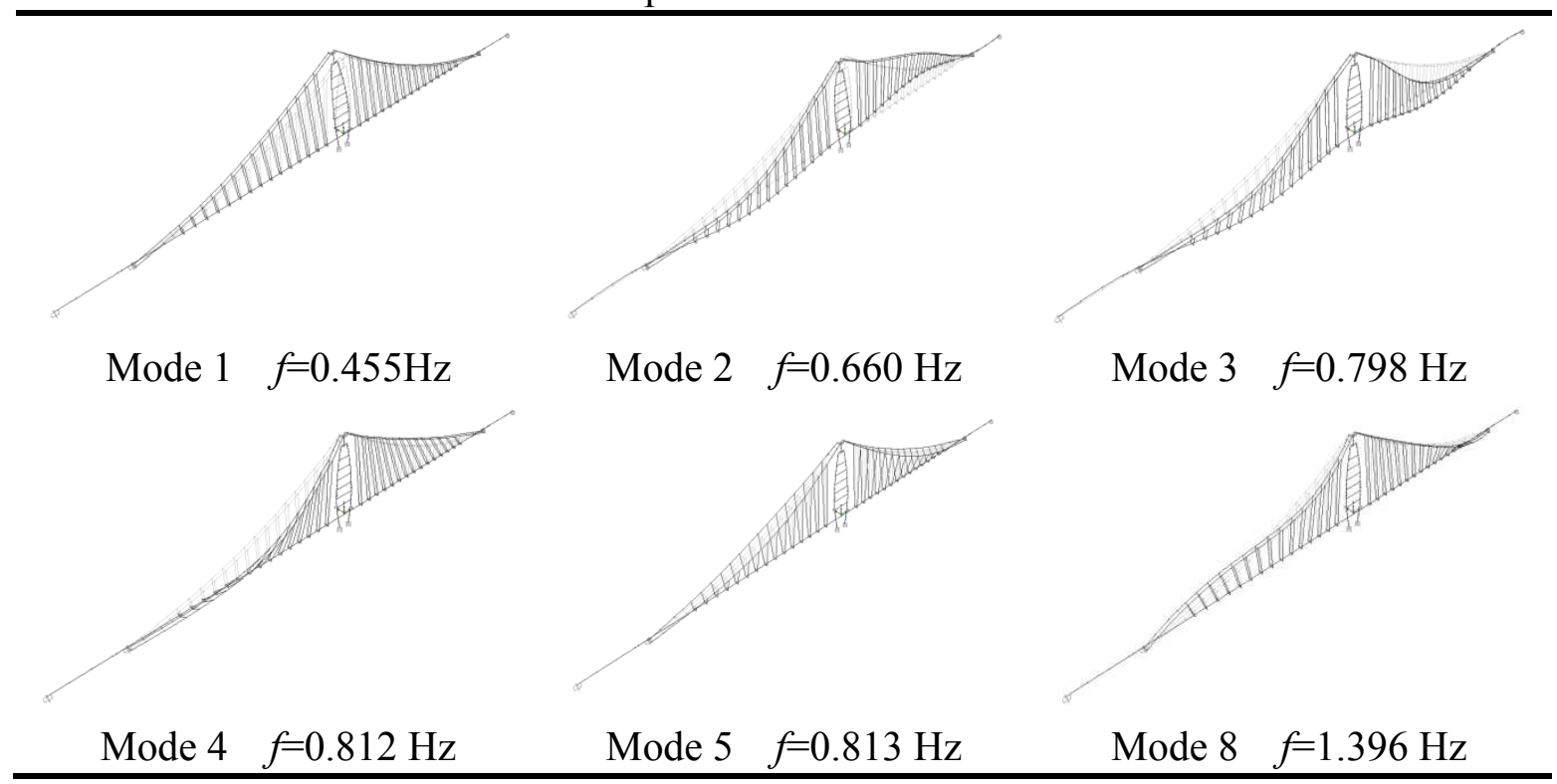

\section{Seismic response analysis based on time history method}

During time history analysis, Rayleigh damping was used to model the damping of the bridge[3]. In Eq. 1, the orthogonal scale factors of Rayleigh damping are: $\alpha=0.07278$ and $\beta=0.00798$, [M] and $[\mathrm{K}]$ is mass matrix and stiffness matrix respectively.

$$
[\mathrm{C}]=\alpha[\mathrm{M}]+\beta[\mathrm{K}]
$$

According to Seismic ground motion parameter zonation map of China and Guidelines for Seismic Design of Highway Bridges[4], the design acceleration response spectrum parameters of this bridge can be checked out and the peak acceleration of the design ground motion is $0.4452 \mathrm{~g}$. An artificial seismic wave as shown in Fig.2 is generated to fit the true response spectrum via trigonometric superposition method. 


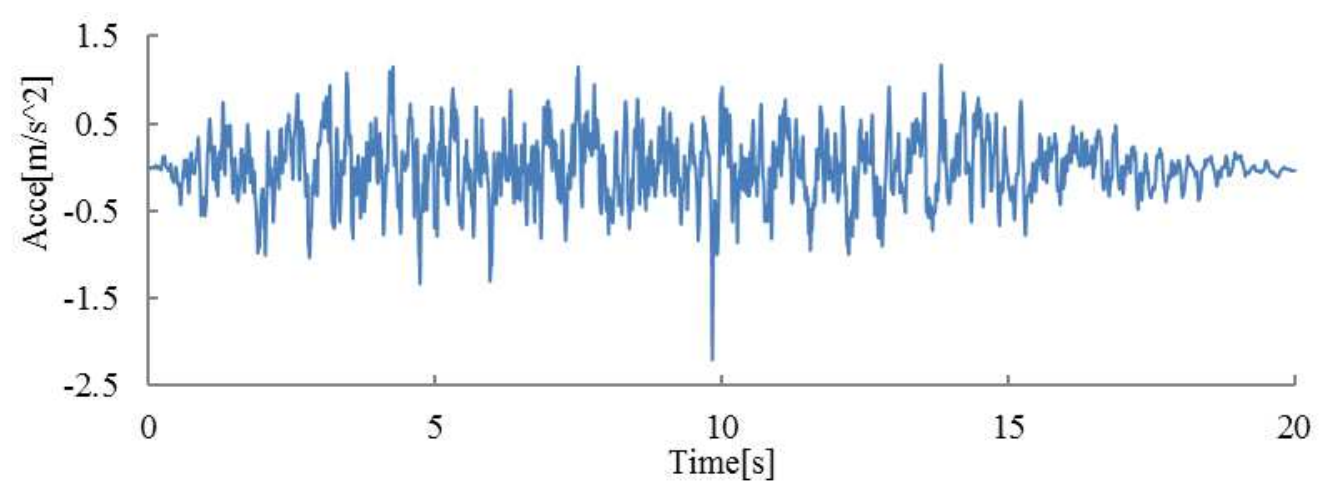

Fig.2 Artificial earthquake wave(EW)

Using the artificial earthquake wave as the ground motion input, including geometry nonlinear effect, seismic response of self anchored suspension bridge is calculated. The EW inputs consider longitudinal, transverse and vertical direction respectively[5]. The calculation result is the following.

$E W$ input in longitudinal direction. The calculation result is list in Table 3 and Table 4 . From Table 3 and Table 4, we can draw a conclusion. In this case, performances of longitudinal and vertical vibration are excited observably. However transverse displacements of any points along with the vertical displacements of pylon are negligible.

It can be seen that the maximum absolute moment response of pylon appears at the root from the above Table s. Thence, the root of pylon is the control section of this load case.

Table 3 The peak value of moment in plane of control section

\begin{tabular}{ccccc}
\hline Position & Min $[\mathrm{kN} \cdot \mathrm{m}]$ & Time[s] & Max $[\mathrm{kN} \cdot \mathrm{m}]$ & Time[s] \\
\hline Intersection of G and P & -63880 & 4.65 & 55740 & 11.60 \\
Root section of pylon & -105500 & 4.65 & 112600 & 9.95 \\
Mid span of girder & -21590 & 5.30 & 17940 & 13.80 \\
\hline
\end{tabular}

Where: $\mathrm{G}$ is short for girder, and $\mathrm{P}$ is short for pylon.

Table 4 The peak value of displacement of control section

\begin{tabular}{ccccc}
\hline Position & Min $[\mathrm{m}]$ & Time[s] & Max [m] & Time[s] \\
\hline Pylon top(Longitudinal) & -0.027 & 9.25 & 0.029 & 13.05 \\
Girder ends(Longitudinal) & $-5.680 \mathrm{E}-03$ & 10.10 & $5.897 \mathrm{E}-03$ & 10.25 \\
Midpoint of main span(Vertical) & -0.024 & 13.80 & 0.027 & 5.35 \\
\hline
\end{tabular}

EW input in transverse direction. In this case, the seismic response result is list in Table 5 and Table 6. Under the transverse EW, the lateral vibration is prime performance of the bridge vibration. It's clear that the root of pylon is the control section from Table 5 and Table 6 . And also, the moment of pylon root section in this case is bigger than that in longitudinal direction input case. The displacement of pylon top point is up to $0.14 \mathrm{~m}$.

Table 5 The peak value of moment out of plane of control section

\begin{tabular}{ccccc}
\hline Position & Min $[\mathrm{kN} \cdot \mathrm{m}]$ & Time $[\mathrm{s}]$ & $\operatorname{Max}[\mathrm{kN} \cdot \mathrm{m}]$ & Time[s] \\
\hline Intersection of G and P & -167900 & 10.35 & 154800 & 10.15 \\
Root section of pylon & -127600 & 14.25 & 119100 & 17.85 \\
Mid-third-point of girder & -126100 & 10.15 & 136100 & 4.85 \\
\hline
\end{tabular}


Table 6 The peak value of displacement of control section

\begin{tabular}{ccccc}
\hline Position & Min[m] & Time[s] & Max[m] & Time[s] \\
\hline Pylon top(Lateral) & -0.128 & 16.75 & 0.140 & 17.85 \\
Girder end(Lateral) & $-8.687-\mathrm{E} 03$ & 4.85 & $7.957 \mathrm{E}-03$ & 5.05 \\
Midpoint of main span(Lateral) & $-6.843 \mathrm{E}-03$ & 10.15 & $6.661 \mathrm{E}-03$ & 4.85 \\
\hline
\end{tabular}

EW input in vertical direction. In this case, the aforesaid EW is multiplied by 0.65 as the ground motion input. The calculation result shows that the seismic response presents the vertical and longitudinal vibration of girder. And the response of pylon is very weak. Above all, in this case, all the response is small, so the result is not list in this paper.

$E W$ input in three directions simultaneously. In this case, earthquake wave is input to analysis seismic response simultaneously. The scale factor of wave in three direction is 1:1:0.65 (longitudinal: transverse: vertical). Fig. 3 shows the envelope of moment of girder and pylon (out of plane). Fig. 4 shows the envelope of moment of girder and pylon (in plane). Fig.5 shows the time history curve of lateral and longitudinal displacement at the top of pylon. Taking these results to be compared with the above results which are calculated separately, it has no obvious change in peak value. That is to say, for this type bridge. The spatial coupled vibration in three dimension is not obviously.

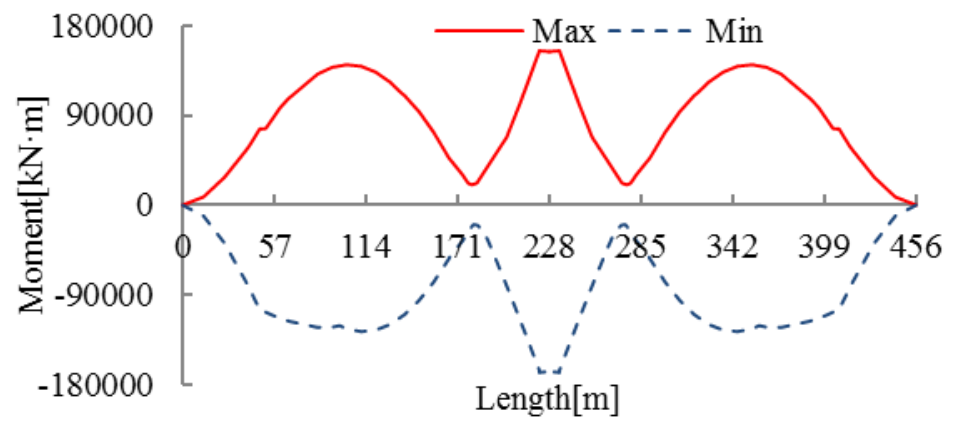

(a) girder

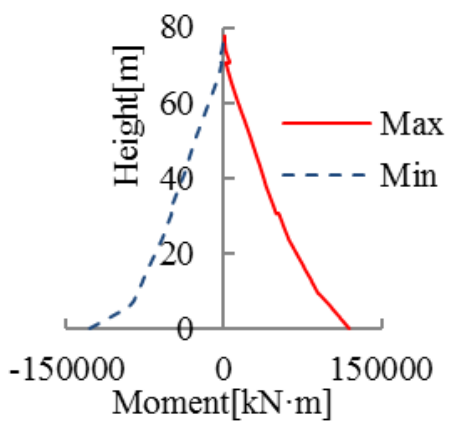

(b) pylon

Fig.3 The envelope of moment of girder and pylon (out of plane)

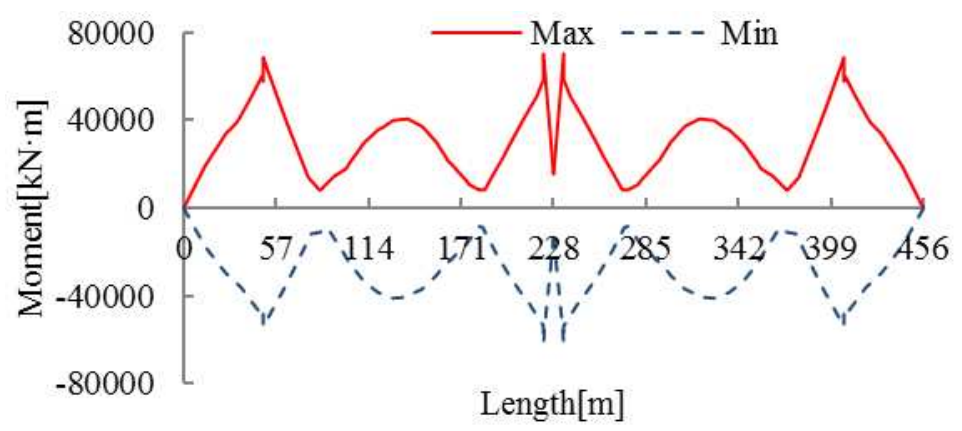

(a) girder

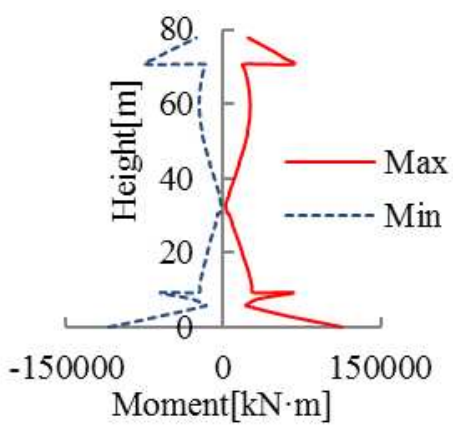

(b) pylon

Fig.4 The envelope of moment of girder and pylon (in plane) 


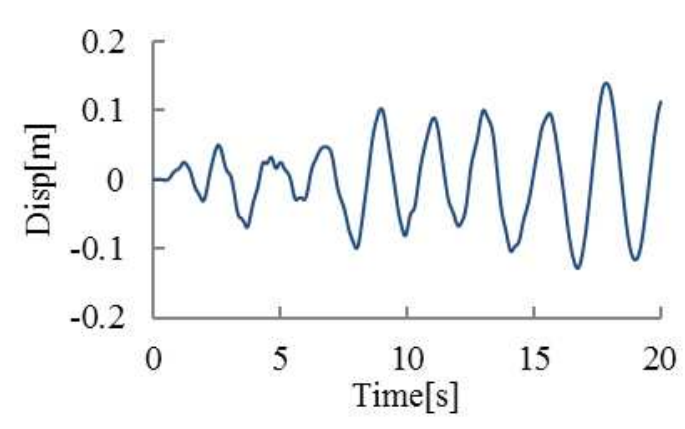

(a) Lateral displacement

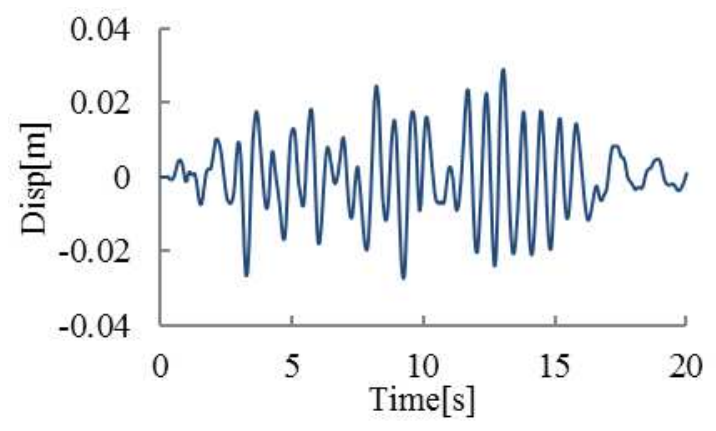

(b) longitudinal displacement

Fig.5 The time history curve of lateral and longitudinal displacement at the top of pylon

\section{Summary}

By studying the seismic performance and dynamic characteristics of the self-anchored suspension bridge, the following conclusions can be drawn:

The performance of lateral sway mode of the pylon for the first mode, which demonstrates the small lateral stiffness of the pylon, is noticeable to be controlled seismic design.

Under the longitudinal earthquake excitation, the longitudinal displacement of pylon is controlled object for this load case. The bottom of the pylon is the most dangerous position with large moment in plane excited by earthquake. Under the transverse earthquake excitation, the lateral displacement of pylon is controlled object for this load case. The bottom of the pylon and midpoint of main span are the most dangerous position with large moment out of plane. Although the internal force and displacement of pylon is relatively small under vertical seismic excitation, it can't be ignored in spatial seismic analysis which include EW input in in three directions since that the vertical load case affects a noticeable impact on girder.

The spatial coupling vibration effect of single tower self-anchored suspension bridge is not obvious. It reached the conclusion that the seismic analysis can be performed under unidirectional EW respectively.

\section{References}

[1] Shi lei, Zhang zhe, Design and mechanical performance analyses of concrete self-anchored suspension bridge, Journal of Dalian University of Technology, March 2003, v43, n2, pp. 202-206.

[2] Li Jianhui , Spatial structural analysis of main saddle for single tower spatial cable self-anchored suspension bridge, Journal of Southeast University, September 2009, v 25, n 3, pp. 372-375.

[3] Ray W. Clough, DYNAMICS OF STRUCTURES, Third Edition, Computers \& Structures, Inc., Berkeley, 2003, pp.234-237.

[4] Transportation Ministry of China, Guidelines for Seismic Design of Highway Bridges (JTJG/T B02-01-2008), 2008, pp.33-40.

[5] Xie $\mathrm{Xu}$, Seismic reponse and earthquake resistant design of bridges, China Communications press, Beijing, 2005, pp.137-139. 